\title{
Approximate Multimodal Dynamic Analysis to Estimate the Seismic Demands of Structures
}

\author{
Benazouz Chikh ${ }^{1(\bowtie)}$, Youcef Mehani ${ }^{1}$, Mohamed Hadid ${ }^{2}$, \\ Abdelmadjid Boubaya $^{3}$, and Berra Ibrahim ${ }^{4}$ \\ ${ }^{1}$ National Earthquake Engineering Research Center, CGS, Algiers, Algeria \\ cheikhpbsd@gmail.com \\ 2 National School of Built and Ground Works Engineering, Kouba, \\ Algiers, Algeria \\ 3 Université Mohamed Khider Biskra, BP 145 RP, 07000 Biskra, Algeria \\ ${ }^{4}$ Universite Mohamed Boudiaf, BP166, M'Sila, Algeria
}

\begin{abstract}
Methods for the seismic demands evaluation of structures require iterative procedures. Many studies dealt with the development of different inelastic spectra with the aim to simplify the evaluation of inelastic deformations and performance of structures. Recently, the concept of inelastic spectra has been adopted in the global scheme of the Performance-Based Seismic Design (PBSD) through Capacity-Spectrum Method (CSM). For instance, the Modal Pushover Analysis (MPA) has been proved to provide accurate results for inelastic buildings to a similar degree of accuracy than the Response Spectrum Analysis (RSA) in estimating peak response for elastic buildings. In this paper, a simplified nonlinear procedure for evaluation of the seismic demand of structures is proposed with its applicability to multi-degree-of-freedom (MDOF) systems. The basic concept is to write the equation of motion of (MDOF) system into series of normal modes based on an inelastic modal decomposition in terms of ductility factor. The accuracy of the proposed procedure is verified against the Nonlinear Time History Analysis (NL-THA) results and Uncoupled Modal Response History Analysis (UMRHA) of a 9-story steel building subjected to El-Centro 1940 (N/S) as a first application. The comparison shows that the new theoretical approach is capable to provide accurate peak response with those obtained when using the NL-THA analysis. After that, a simplified nonlinear spectral analysis is proposed and illustrated by examples in order to describe inelastic response spectra and to relate it to the capacity curve (Pushover curve) by a new parameter of control, called normalized yield strength coefficient $(\boldsymbol{\eta})$. In the second application, the proposed procedure is verified against the NL-THA analysis results of two buildings for 80 selected real ground motions.
\end{abstract}

\section{List of Symbols}

$\mathrm{M}$

$\mathrm{C}$

$\mathrm{F}$

$\ddot{\mathrm{x}}_{\mathrm{g}}(\mathrm{t})$

$\mathrm{m}_{\mathrm{i}}$

$\mathrm{F}_{\mathrm{i}}$
Mass matrice

Damping matrice

Resisting force vector

Earthquake acceleration

Mass of the ith level

Resisting force of the ith level 


$\begin{array}{ll}\mathrm{k}_{\mathrm{e}, \mathrm{i}} & \text { Elastic stiffness of the ith level } \\ \mathrm{k}_{\mathrm{p}, \mathrm{i}} & \text { Postyield stiffness of the ith level } \\ \mathrm{Q}_{\mathrm{i}} & \text { Yield strength of the ith level } \\ \mathrm{x}_{\mathrm{y}, \mathrm{i}} & \text { Yield displacement of the ith level } \\ \mathrm{K}_{\mathrm{p}} & \text { Postyield stiffness matrix } \\ \mathrm{Q} & \text { Yield strength vector } \\ \mathrm{z} & \text { Dimensionless variable } \\ \mathrm{A}=1 & \\ \mathrm{~B}=0.1 & \\ \lambda=0.9 & \\ \beta=6 & \text { Modal coordinate } \\ \gamma_{\mathrm{n}}(\mathrm{t}) & \text { nth natural vibration mode of the structure } \\ \phi_{\mathrm{n}} & \text { Natural vibration frequency } \\ \omega_{\mathrm{n}} & \text { Damping ratio } \\ \xi_{\mathrm{n}} & \text { Post-to-preyield stiffness ratio } \\ \alpha_{\mathrm{n}} & \text { Yield strength } \\ \mathrm{Q}_{\mathrm{n}}=\phi_{\mathrm{n}}^{\mathrm{t}} \mathrm{Q} & \text { Effective mass } \\ \mathrm{M}_{\mathrm{n}}^{*}=\mathrm{L}_{\mathrm{n}} & \text { Modal participation factor } \\ \Gamma_{\mathrm{n}} & \\ \mathrm{L}_{\mathrm{n}}=\phi_{\mathrm{n}}^{\mathrm{T}} \mathrm{m} \mathrm{m} / \phi_{\mathrm{n}}^{\mathrm{T}} \mathrm{m} \phi_{\mathrm{n}} \mathrm{n} \mathrm{n} \mathrm{n} & \\ \mu_{n} & \text { Ductility demand } \\ \mathrm{D}_{\mathrm{n}, \mathrm{m}} & \text { Peak displacement } \\ \mathrm{D}_{\mathrm{n}, \mathrm{y}} & \text { Yield displacement } \\ \mathrm{q}_{\mathrm{n}} & \text { Yield strength coefficient } \\ \mathrm{S}_{\mathrm{an}} & \text { Spectral acceleration } \\ \mathrm{V}_{\mathrm{bn}} & \text { Base shear } \\ \phi_{\mathrm{rn}} & \text { Amplitude of } \phi_{\mathrm{n}} \\ \mathrm{x}_{\mathrm{rn}} & \text { Roof displacement } \\ & \end{array}$

\section{Introduction}

Several simple evaluation methods have been proposed as an alternative to the complex nonlinear dynamic analysis to estimate the seismic demands of structures (Gülkan and Sözen 1974; Freeman et al. 1975; Newmark and Hall 1982; Fajfar and Fischinger 1988; Kowalsky 1994; Sasaki et al. 1998; Fajfar 1999; Gupta and Kunnath 2000; Albanesi et al. 2000; Priestley and Kowalsky 2000; Miranda 2001; Chopra and Goel 2001; Lin and Chang 2003; Maja and Fajfar 2012; Chikh et al. 2014; Zerbin and Aprile 2015; Kazaz 2016). The basic idea of these methods is to relate the structural capacity to the physical basis of elastic or inelastic demand spectra, as the Capacity Spectrum Method (ATC-40 1996) and its different implementations.

The seismic demands assessment methods are generally based on the nonlinear static analysis, where the structure is subjected to lateral loads increasing monotonically 
over the entire height until a predetermined target displacement. The distribution of these forces and the target displacement are based on the assumption that the response is controlled only by the fundamental mode, knowing that constant distribution of forces will not capture the contribution of higher modes in the overall structural response. Several researchers have proposed adaptive force distributions that attempt to follow more closely the distribution of inertial forces over time (Fajfar and Fischinger 1988; Baracci et al. 1997; Gupta and Kunnath 2000). Attempts have also been made to consider more than the fundamental mode of vibration in the Pushover analysis (Paret et al. 1996; Sasaki et al. 1998; Gupta and Kunnath 2000; Matsumori et al. 1999; Chopra and Goel 2001).

In this paper an inelastic equation of motion of MDOF system will be rewritten in terms of the ductility to obtain an approximate multimodal dynamic analysis (AMDA) that consider the ductility factor as the inelastic response of the system.

\section{Approximate Multimodal Dynamic Analysis}

\subsection{Inelastic Modal Decomposition in Terms of Ductility}

The matrix form of differential equations governing the response of a MDOF system to earthquake induced ground motion can be written as:

$$
M \ddot{x}(t)+C \dot{x}(t)+F(x, \text { sign } \dot{x})=-M i \ddot{x}_{g}(t)
$$

where $\mathrm{M}$ and $\mathrm{C}$ are the mass and damping matrices respectively, $\mathrm{F}$ denotes the resisting force vector, $l$ is the vector of earthquake influence coefficients and $\ddot{x}_{g}(t)$ denotes the earthquake acceleration. The damping matrix $\mathrm{C}$ would not be needed in this analysis of earthquake response; instead modal damping ratios suffice.

The resisting force vector $\mathrm{F}$ is defined as the sum of the linear and the hysteretic parts as represented in Fig. 1 (Benazouz et al. 2012, 2016).

$$
F=K_{p} x+Q z(x, \dot{x})
$$

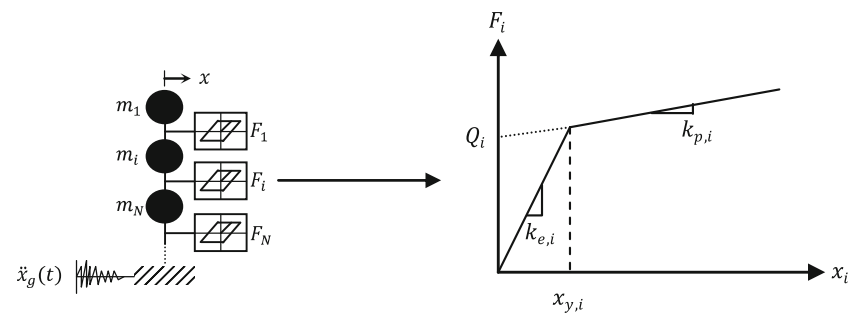

Fig. 1. Example of the resisting force of a MDOF system 
where, $\mathrm{m}_{\mathrm{i}}, \mathrm{F}_{\mathrm{i}}, \mathrm{k}_{\mathrm{e}, \mathrm{i}}, \mathrm{k}_{\mathrm{p}, \mathrm{i}}, \mathrm{Q}_{\mathrm{i}}$ and $\mathrm{x}_{\mathrm{y}, \mathrm{i}}$ are the mass, resisting force, elastic stiffness, postyield stiffness, yield strength and yield displacement of the ith level, respectively.

In Eq. (2), the resisting force is a vector for MDOF systems, $K_{p}$ is the postyield stiffness matrix, $\mathrm{Q}$ the yield strength vector, and $\mathrm{z}$ a dimensionless variable that characterizes the Bouc-Wen model of hysteresis (Wen 1976). It is given by:

$$
\dot{z}=\frac{\dot{x}}{x_{y}}\left[A-|z|^{\lambda}(B \operatorname{sign}(\dot{x} z)+\beta)\right]
$$

where, $\mathrm{x}_{\mathrm{y}}$ is the yield displacement vector; $\mathrm{A}, \mathrm{B}, \lambda$ and $\beta$ are the parameters that control the shape of the hysteresis loop which are taken as: $\mathrm{A}=1, \mathrm{~B}=0.1, \lambda=0.9$ and $\beta=6$ for bilinear system, $\operatorname{sign}($.$) is the sign function (Wen 1976).$

Using Eqs. (1) and (2) we get:

$$
M \ddot{x}(t)+C \dot{x}(t)+K_{p} x(t)+Q z(x, \dot{x})=-M i \ddot{x}_{g}(t)
$$

The decomposition of the MDOF system as a series of normal modes is reasonable. Equation (5) is used to involve the influence of higher modes in the peak and overall response of the structure (Chopra 2007).

$$
x(t)=\sum_{n} x_{n}(t)=\sum_{n} \phi_{n} \gamma_{n}(t)
$$

where: $\gamma_{n}(t)$ is the modal coordinate and $\phi_{n}$ is the nth natural vibration mode of the structure.

Substituting Eq. (4) into Eq. (5), using the mass, stiffness and classical damping orthogonality mode properties, we obtain the following differential equation for the single-degree-of-freedom (SDOF) system response:

$$
\ddot{\gamma}_{n}(t)+2 \xi_{n} \omega_{n} \dot{\gamma}_{n}(t)+\alpha_{n} \omega_{n}^{2} \gamma(t)+\frac{Q_{n} z_{n}(\gamma, \dot{\gamma})}{M_{n}^{*}}=-\Gamma_{n} \ddot{x}_{g}(t)
$$

where, $\omega_{\mathrm{n}}$ is the natural vibration frequency, $\xi_{\mathrm{n}}$ the damping ratio, $\alpha_{\mathrm{n}}$ the post-to-preyield stiffness ratio, $Q_{n}=\phi_{n}^{t} Q$ the yield strength, $M_{n}^{*}=\frac{L_{n}}{\Gamma_{n}}$, the effective mass, $\Gamma_{\mathrm{n}}=\phi_{\mathrm{n}}^{\mathrm{T}} \mathrm{ml} / \phi_{\mathrm{n}}^{\mathrm{T}} \mathrm{m} \phi_{\mathrm{n}}$ the modal participation factor and $\mathrm{L}_{\mathrm{n}}=\phi_{\mathrm{n}}^{\mathrm{T}} \mathrm{m} \mathrm{r}$ for the $\mathrm{nth}$ natural vibration mode.

The solution, $\gamma_{\mathrm{n}}$, of Eq. (6) is given by (Chopra 2007):

$$
\gamma_{n}(t)=\Gamma_{n} D_{n}(t)
$$

With this approximation, the solution of Eq. (6) can be expressed by Eq. (7), where the displacement $D_{n}(t)$ of the SDOF system can be assessed by the following equation:

$$
\ddot{D}_{n}(t)+2 \xi_{n} \omega_{n} \dot{D}_{n}(t)+\alpha_{n} \omega_{n}^{2} D(t)+\frac{Q_{n} z_{n}(D, \dot{D})}{\Gamma_{n} M_{n}^{*}}=-\ddot{x}_{g}(t)
$$


This ductility demand (or ductility factor) for the SDOF bilinear system is expressed as:

$$
\mu_{n}=\frac{D_{n, m}}{D_{n, y}}
$$

where: $D_{n, m}$ is the peak displacement and $D_{n, y}$ is the yield displacement.

It seems worth to associate for each instantaneous inelastic displacement $D_{n}(t)$ an instantaneous ductility factor $\mu_{\mathrm{n}}(\mathrm{t})$ defined as:

$$
\left\{\begin{array}{l}
D_{n}(t)=\mu_{n}(t) \times D_{n, y} \\
\dot{D}_{n}(t)=\dot{\mu}_{n}(t) \times D_{n, y} \\
\ddot{D}_{n}(t)=\ddot{\mu}_{n}(t) \times D_{n, y}
\end{array}\right.
$$

Equation (8) can be rewritten in terms of ductility factor $\mu_{n}$, by substituting Eq. (10) in Eq. (8) and dividing by $\mathrm{D}_{\mathrm{n}, \mathrm{y}}$, which gives:

$$
\ddot{\mu}_{n}+2 \xi_{n} \omega_{n} \dot{\mu}_{n}+\alpha_{n} \omega_{n}^{2} \mu_{n}+\frac{q_{n} g z_{n}(\mu, \dot{\mu})}{D_{n, y}}=-\frac{1}{D_{n, y}} \ddot{x}_{g}(t)
$$

$\mathrm{q}_{\mathrm{n}}$ is the yield strength coefficient for the nth natural vibration mode of the structure (defined as yield strength divided by $\mathrm{L}_{\mathrm{n}}$ ).

$$
q_{n}=\frac{Q_{n}}{L_{n}}
$$

Also, Eq. (3) may be expressed in terms of ductility factor $\mu_{\mathrm{n}}$ as:

$$
\dot{z}=\dot{\mu}_{n}\left[A-|z|^{\lambda}(B \operatorname{sign}(\dot{x} z)+\beta)\right]
$$

The term $\frac{\mathrm{q}_{\mathrm{n}} \mathrm{g}}{\mathrm{D}_{\mathrm{n}, \mathrm{y}}}$ in Eq. (11) is rewritten as:

$$
\frac{q_{n} g}{D_{n, y}}=\omega_{n}^{2}\left(1-\alpha_{n}\right)
$$

Substituting Eq. (14) into Eq. (11) gives:

$$
\ddot{\mu}_{n}+2 \xi_{n} \omega_{n} \dot{\mu}_{n}+\alpha_{n} \omega_{n}^{2} \mu_{n}+\omega_{n}^{2}\left(1-\alpha_{n}\right) z_{n}(\mu, \dot{\mu})=-\frac{\omega_{n}^{2}\left(1-\alpha_{n}\right)}{q_{n} g} \ddot{x}_{g}(t)
$$

It can be observed from Eq. (15) that for a given ground acceleration, $\mu_{n}(t)$ depends on $\xi_{n}, \omega_{n}, \alpha_{n}$ and $q_{n}$ of the nth natural vibration mode.

Based on Eqs. (5) and (7) and dividing by $\mathrm{D}_{\mathrm{n}, \mathrm{y}}$ give the ductility demand and the displacement of the original structure: 


$$
\mu(t)=\sum_{n} \phi_{n} \Gamma_{n} \mu_{n}(t) \quad x(t)=\sum_{n} \phi_{n} \Gamma_{n} D_{n}(t)
$$

Figure 2 illustrates the technique of uncoupling the equation of motion in terms of ductility factor characterizing the MDOF system. The response of a MDOF system to earthquake ground motion can be computed as a function of time by the procedure just developed the approximate multimodal dynamic analysis (AMDA), which is detailed in the next application. The proposed approximate analysis consists to solve Eq. (15)

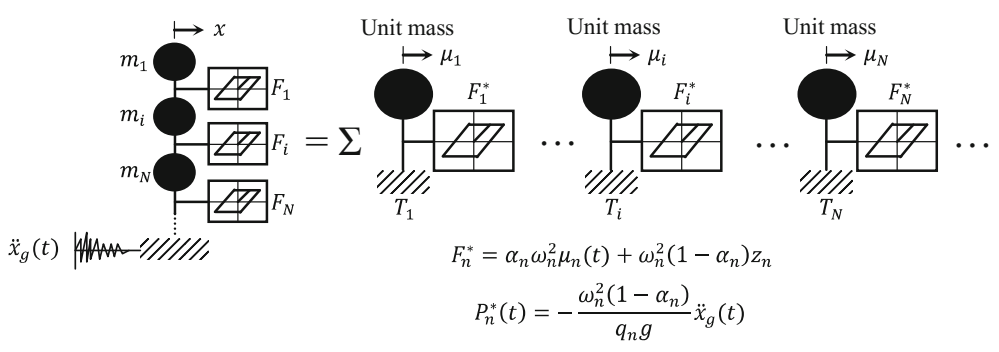

Fig. 2. Approximate multimodal dynamic procedure for MDOF structures

for $\ddot{x}_{g}(t)$ that will be multiplied by a new factor $-\omega_{n}^{2}\left(1-\alpha_{n}\right) / q_{n} g$ to constitute a new excitation for the structure to determine finally the total response quantities of interest by using Eq. (16).

\subsection{Application}

In recent years Chopra and Goel (2002) assessed the strength variation of several procedures including the modal Pushover analysis (MPA), that they developed. The MPA analysis is based on structural dynamics theory. Its accuracy and reliability in estimating the peak response of inelastic MDOF systems has been evaluated extensively by the authors. Goel and Chopra (2004) analyzed and evaluated the response of several procedures for nonlinear static analysis, including Pushover analysis where only fundamental mode was taken into account.

The accurate of the proposed procedure is evaluated for a 9-story SAC steel building (Chopra and Goel 2001). The 'exact' response of a rigorous nonlinear time history analysis (NL-THA) is compared with the response obtained by the approximate multimodal dynamic analysis (AMDA).

The 9-story structure meets the seismic code requirements and represents typical medium-rise buildings designed for the Los Angeles, California region. The Pushover curves of this structure presented in (Chopra and Goel 2001) are sufficient for the objectives of this study. The selected structure is tested and detailed in this section when subjected to one time and half (1.5) El Centro 1940 ground motion. The properties of the first three modes of vibration are summarized in Table 1. 
Table 1. Properties of modal inelastic SDOF systems

\begin{tabular}{l|l|l|l}
\hline Properties & Mode 1 & Mode 2 & Mode 3 \\
\hline$L_{n}(\mathrm{~kg})$ & 2736789 & -920860 & 696400 \\
\hline$\Gamma_{n}$ & 1.36 & -0.5309 & 0.2406 \\
\hline$M_{n}^{*}(\mathrm{~kg})$ & 3740189 & 488839.1 & 167531.5 \\
\hline$D_{n, y}(\mathrm{~cm})$ & 26.51 & 18.65 & 19.12 \\
\hline$T_{n}(\mathrm{sec})$ & 2.2671 & 0.8525 & 0.4927 \\
\hline$\alpha_{n}$ & 0.19 & 0.13 & 0.14 \\
\hline$k_{n}(\mathrm{kN} / \mathrm{cm})$ & 210.3867 & 500.2020 & 1132.6086 \\
\hline$\xi_{n}(\%)$ & 1.948 & 1.103 & 1.136 \\
\hline$Q_{n}(\mathrm{kN})$ & 6168.977 & 4374.343 & 4414.347 \\
\hline$q_{n}(\mathrm{~g})$ & 0.168 & 0.912 & 2.685 \\
\hline
\end{tabular}

The capacity curves of the three first modes are shown in Fig. 3. Next, the Pushover curves are transformed to equivalent SDOF systems (see Fig. 3). The conversion of the idealized Pushover curve to the force-displacement, (see Fig. 3(b)) for the nth-mode of inelastic SDOF system is obtained by using $\left(F_{n}^{*}-D_{n, y}\right)$ :

$$
S_{a n}=\frac{V_{b n}}{M_{n}^{*}}=F_{n}^{*}, \quad D_{n}=\frac{x_{r n}}{\Gamma_{n} \phi_{r n}}
$$

In which $S_{a n}$ is the spectral acceleration, $V_{b n}$ the base shear, $\phi_{\mathrm{rn}}$ is the amplitude of $\phi_{\mathrm{n}}$ and $\mathrm{x}_{\mathrm{rn}}$ the roof displacement.

The approximate multimodal dynamic analysis of the structure starts with obtaining the multimodal Pushover curves of the MDOF system subjected to lateral forces distributed over the building height. In the proposed procedure, the movements will be
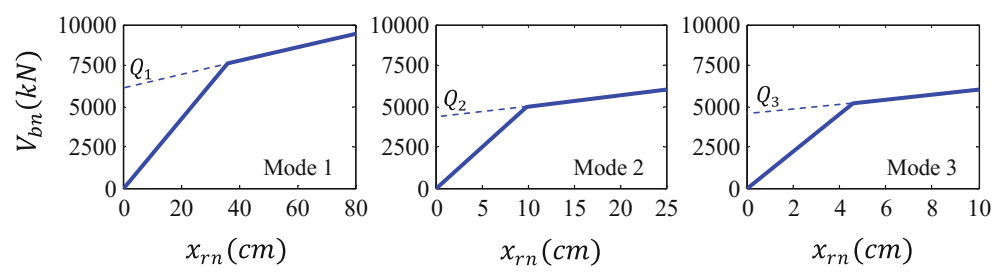

(a) Capacity Curve
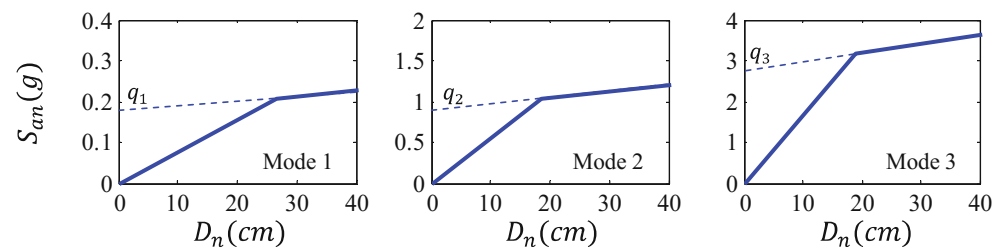

(b) $S_{a n}-D_{n}$ Relationship Curve

Fig. 3. Modal pushover curves and capacity diagrams for the first three modes 

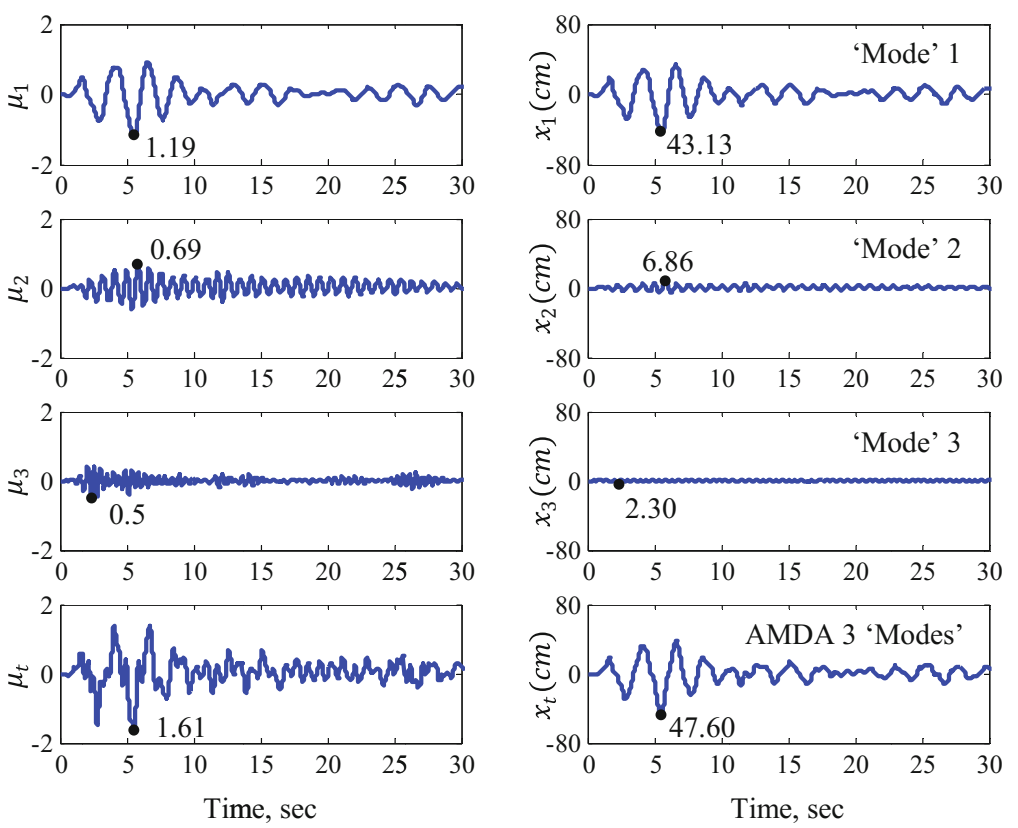

Fig. 4. Response histories of ductility demand and roof displacement from the proposed procedure for $1.5 \times$ El Centro ground motion: first three modal responses and total (all modes) response

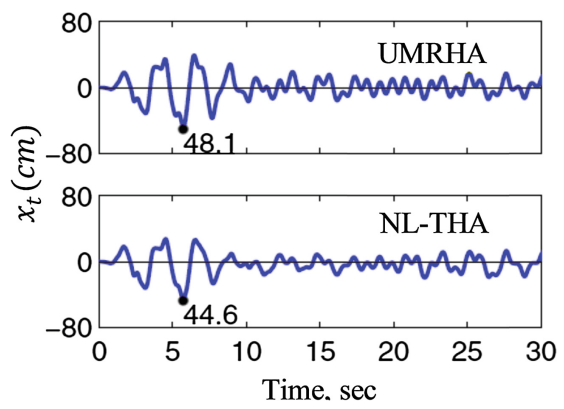

Fig. 5. Total response histories of roof displacement for $1.5 \times$ El Centro ground motion from the UMRHA and NL-THA (Chopra and Goel 2001)

decomposed in the form of a series of normal modes in terms of the ductility demand. Equation (15) is solved, and the resulting ductility demand history is decomposed into its "modal" components. The obtained response histories of ductility demand and roof displacements for the three first modes of the selected building subject to 1.5 times El Centro ground motion (N/S) component $(\mathrm{PGA}=0.32 \mathrm{~g}, \mathrm{PGV}=36.14 \mathrm{~cm} / \mathrm{sec}$, and $\mathrm{PGD}=21.34 \mathrm{~cm})$ are shown in Fig. 4. 
The proposed procedure is evaluated by comparing the computed displacements histories according to Eqs. (15) and (16), considering three modes with those estimated by the NL-THA analysis and the Uncoupled Modal Response History Analysis (UMRHA) that was developed by Chopra and Goel (2001) (see Figs. 4 and 5).

Following the AMDA procedure aforementioned, the total response is determined using the UMRHA and NL-THA ("exact"). Figure 4 shows the ductility demand, also is shown in the same figure the roof displacements time histories. It is clear from the comparison shown in Figs. 4 and 5 that the AMDA gives results in good agreement with the NL-THA.

\section{Conclusion}

An approximate procedure for seismic demands assessment of MDOF system has been developed and its accuracy was verified by examples. An inelastic modal decomposition in terms of ductility has been developed to construct the Approximate Multimodal Dynamic Analysis. That was verified using the seismic response of an example steel frame structure for which capacity curve data is available. The results indicated that more reliable displacement predictions are obtained from the proposed method.

The base shear-roof displacement $\left(\mathrm{V}_{\mathrm{bn}}-\mathrm{x}_{\mathrm{rn}}\right)$ curve is developed from a Pushover analysis. This Pushover curve is idealized as a bilinear force-deformation relation for the nth mode of inelastic SDOF system. This idealization is used to determine the yield strength coefficient $\mathrm{q}_{\mathrm{n}}$ and the post-to-preyield stiffness ratio $\alpha_{\mathrm{n}}$ to estimate the ductility demand. The peak deformation of this SDOF system, determined by the Approximate Multimodal Dynamic Analysis, is used to determine the target value of roof displacement at which the seismic response is determined by the Pushover analysis. The total demand is determined by the sum of responses of the first three modes.

\section{References}

Albanesi, T., Nuti, C., Vanzi, I.: A simplified procedure to assess the seismic response of nonlinear structures. Earthq. Spectra 16(4), 715-734 (2000)

ATC: Seismic evaluation and retrofit of concrete buildings. Applied Technology Council, California (1996)

Benazouz, C., Moussa, L., Ali, Z.: Ductility and inelastic deformation demands of structures. J. Struct. Eng. Mech. 42(5), 631-644 (2012)

Bracci, J.M., Kunnath, S.K., Reinhorn, A.M.: Seismic performance and retrofit evaluation for reinforced concrete structures. J. Struc. Eng. ASCE 123(1), 3-10 (1997)

Chikh, B., Leblouba, M., Mehani, Y., Kibboua, A., Hadid, M., Zerzour, A.: Ductility spectrum method for design and verification of structures: single-degree-of-freedom bilinear systems. In: Proceedings of the 15th European Conference on Earthquake Engineering, Istanbul, Turkey, August 2014

Chikh, B., Mehani, Y., Leblouba, M.: Simplified procedure for seismic demands assessment of structures. J. Struct. Eng. Mech. 59(3), 455-473 (2016) 
Chopra, A.K., Goel, R.K.: A Modal Pushover Analysis Procedure to Estimate Seismic Demands for Buildings: Theory and Preliminary Evaluation. PEER, Berkely (2001). 2001/03

Chopra, A.K., Goel, R.K.: A modal pushover analysis procedure for estimating seismic demands for buildings. Earthq. Eng. Struct. Dyn. 31(3), 561-582 (2002)

Chopra, A.K., Chatpan, C.: Inelastic deformation ratios for design and evaluation of structures: single-degree-of-freedom bilinear systems. J. Struct. Eng. 130(9), 1309-1319 (2004)

Chopra, A.K.: Dynamics of Structures - Theory and Applications to Earthquake Engineering, 3rd edn. Prentice Hall, Upper Saddle River (2007)

Fajfar, P., Fischinger, M.: N2 a method for nonlinear seismic analysis of regular structures. In: Proceedings of 9th World Conference on Earthquake Engineering, Tokyo-Kyoto, Japan, vol. 5, pp. 111-116 (1988)

Fajfar, P.: Capacity spectrum method based on inelastic demand spectra. Earthq. Eng. Struct. Dyn. 28(9), 979-993 (1999)

Freeman, S.A., Nicoletti, J.P., Tyrell, J.V.: Evaluation of existing buildings for seismic risk-a case study of Puget Sound Naval Shipyard. In: Proceedings of 1st US National Conference on Earthquake Engineering, Berkeley, USA, pp. 113-122 (1975)

Gülkan, P., Sözen, M.: Inelastic response of reinforced concrete structures to earthquake motions. ACI J. Proc. 71(12), 604-610 (1974)

Gupta, B., Kunnath, S.K.: Adaptive spectra-based pushover procedure for seismic evaluation of structures. Earthq. Spectra 16(2), 367-392 (2000)

Kazaz, L.: Seismic deformation demands on rectangular structural walls in frame-wall systems. Earthq. Struct. 10(2), 329-350 (2016)

Kowalsky, M.J.: Displacement-based design - a methodology for seismic design applied to RC bridge columns. Master's thesis, University of California at San Diego, La Jolla, California (1994)

Lin, Y.Y., Chang, K.C.: An Improved Capacity Spectrum Method for ATC-40. Earthq. Eng. Struct. Dyn. 32(13), 2013-2025 (2003)

Maja, K., Fajfar, P.: The extended N2 method considering higher mode effects in both plan and elevation. Bull. Earth. Eng. 10(2), 695-715 (2012)

Matsumori, T., Otani, S., Shiohara, H., Kabeyasawa, T.: Earthquake member deformation demands in reinforced concrete frame structures. In: Proceeding U.S.-Japan Workshop on Performance-Based Earthquake Engineering Methodology for R/C Building. Structures, Maui, Hawaii, pp. 79-94 (1999)

Miranda, E.: Estimation of inelastic deformation demands of SDOF systems. J. Struct. Eng. 127 (9), 1005-1012 (2001)

Newmark, N.M., Hall, W.J.: Earthquake Spectra and Design. Earthquake Engineering Research Institute, Berkeley (1982)

Paret, T.F., Sasaki, K.K., Eilbekc, D.H., Freeman, S.A.: Approximate inelastic procedures to identify failure mechanisms from higher mode effects. In: Proceeding of the 11th World Conference on Earthquake Engineering, Paper no. 966, Acapulco, Mexico (1996)

Priestley, M.J., Kowalsky, M.J.: Direct displacement-based seismic design of concrete buildings. Bull N. Z. Soc. Earthq. Eng. 33(4), 421-444 (2000)

Sasaki, K.K., Freeman, S.A., Paret, T.F.: Multimode pushover procedure (MMP) - a method to identify the effects of higher modes in a pushover analysis. In: Proceeding of the 6th U.S. National Conference on Earthquake Engineering, Seattle, Washington (1998)

Wen, Y.K.: Method for random vibration of hysteretic systems. J. Eng. Mech. 102(2), 249-263 (1976)

Zerbin, M., Aprile, A.: Sustainable retrofit design of RC frames evaluated for different seismic demand. Earthq. Struct. 9(6), 1337-1353 (2015) 